\title{
Traumatic Brain Injury with Personality Change: a Challenge to Mental Capacity Law in England and Wales
}

\author{
Demian Whiting ${ }^{1}$ (i) \\ Received: 10 September 2019 / Accepted: 22 October 2019 / Published online: 5 December 2019 \\ (C) The Author(s) 2019
}

\begin{abstract}
It is well documented that people with moderate-to-severe traumatic brain injury (TBI) can undergo personality changes, including becoming more impulsive in terms of how they behave. Legal guidance and academic commentary support the view that impulsiveness can render someone decisionally incompetent as defined by English and Welsh law. However, impulsiveness is a trait found within the healthy population. Arguably, impulsiveness is also a trait that gives rise to behaviours that should normally be tolerated even when they cause harm to the person enacting the behaviours. The purpose of this paper is to show why both of these considerations present as significant challenges to the law in England and Wales.
\end{abstract}

Keywords Mental capacity $\cdot$ Traumatic brain injury $\cdot$ Personality change $\cdot$ Impulsivity $\cdot$ Deliberation $\cdot$ Sovereignty rights

\section{Introduction}

A key legal and ethical tenet of a liberal society has it that people be allowed to make decisions regarding significant areas of their lives for themselves, such as whether to undergo a healthcare procedure or to make a financial transaction. Nevertheless, many jurisdictions have law that describes circumstances in which people are to be deemed incapable of making decisions, and where decisions are to be made on their behalf by a surrogate decision-maker. The capability to make decisions for oneself (and which is referred to by such terms as 'mental capacity', 'decision-making capacity' and 'competence'; these and cognate terms are used interchangeably in what follows) is usually taken to comprise certain decisional abilities, including those involved in understanding, memory, and deliberation.

It is important to note that the abilities in question reflect lawmakers' attempts to set the bar for capacity at an appropriate level. For lawmakers (parliament, the courts), the question of whether a person is competent is not that of whether a person has decisional abilities that would satisfy a decisional ideal. Rather, it is that of whether regarding a person as competent is likely to achieve the right balance between various and often competing goods (those pertaining to respecting

Demian Whiting

d.whiting@hull.ac.uk; demian.whiting@hyms.ac.uk

1 Hull York Medical School, University of Hull, Hull HU6 7RX, UK people's sovereignty rights and those pertaining to protecting vulnerable people from coming to harm, for instance). For this reason, the law has sought to avoid adopting an idealized model of capacity, such as one requiring people to be able to make 'rational' decisions (Culver and Gert 1990, 2004), on the grounds that such a model would be too demanding and would likely entail that few people have capacity.

Yet we should always remain open to the possibility that the law has got it wrong, that reasons might exist for thinking that despite lawmakers' best efforts, the bar for capacity has been set too high or low. One way to evaluate whether the law has set the bar at the right level is by considering groups of people who would qualify as decisionally incompetent according to existing law, and to ask whether these people ought to be considered incompetent by law. For instance, we might ask whether regarding such people as decisionally incompetent constitutes a wrongful violation of these people's sovereignty rights, their rights to make decisions in a way that accords with their own preferences, desires and values.

Now, it is well documented that people with moderate-tosevere traumatic brain injury (TBI) can undergo personality changes, including becoming more impulsive (see, for instance, Crowe 2008, McAllister 2008, Rao et al. 2009, Rochat et al. 2013). ${ }^{1}$ Note we are speaking of what we might

\footnotetext{
${ }^{1}$ TBI can be mild, moderate or severe (depending on the extent of damage to the brain and severity of symptoms after injury). Although mild TBI can lead to behavioural and mood changes, personality change concomitant to brain injury is more often associated with moderate-to-severe TBI, and so, it is the more severe forms of TBI with which this paper is principally concerned.
} 
think of as changes in personality traits, that is to say, changes in characteristic patterns of thoughts, feelings and behaviours, and which in cases of moderate-to-severe TBI can include being at increased risk of behaving in impulsive ways. Legal guidance and academic commentary support the view that impulsiveness can render someone incompetent as defined by English and Welsh law. However, impulsiveness is a trait found within the healthy population and not only in those who suffer psychological injury. Arguably, impulsiveness is also a trait that gives rise to behaviours that normally should be tolerated even when they result in poor outcomes for the person enacting the behaviours. The purpose of this paper is to show why both these considerations present as significant challenges to the law in England and Wales.

The next section says something more about what decision-making capacity is and what role a determination of capacity or incapacity serves in law. The section following explains how moderate-to-severe TBI with personality change can rob people of their capacity to make important decisions for themselves. The penultimate section advances two challenges that cases of TBI with personality change present for the law and especially for the criteria for capacity as spelled out by the law. Finally, the concluding section outlines a number of additional considerations that are pertinent to answering the question of whether the law ought to change in light of the challenges raised in the paper.

\section{Decision-Making Capacity}

The relevant consideration regarding whether someone has decisional capacity is that of whether the person satisfies legal criteria for capacity. In the context of England and Wales (though not Scotland and Northern Ireland, which are governed by separate law), this is a matter of whether a person has a number of abilities as outlined by the Mental Capacity Act 2005 (MCA). These are the abilities to understand information relevant to the decision, to retain the information, to use or weigh the information as part of the process of making the decision and to communicate the decision (orally or by other means). ${ }^{2}$

A number of observations might be made. First, mental capacity law uses a functional or process test for capacity

\footnotetext{
$\overline{2}$ Although the focus of this paper is on English and Welsh law and its Mental Capacity Act, it is worth remarking that the arguments advanced are likely to be relevant to the law of a number of other liberal jurisdictions, including the USA, which conceptualize decisional capacity in a similar way, namely to comprise abilities such as understanding and appreciation, retention of information and deliberation of risks and benefits (Buchanan 2004, Grisso and Appelbaum 1998). Indeed, as Owen et al point out, the 'MCA standard can itself been seen as a close variant on the standard of competence for treatment decisions distilled by Grisso and Appelbaum (1998) on the basis of a systematic study of case law in the United States' (2018a:2)
}

and not one that is based on decision outcomes. The reasoning for this relates to one of the underlying principles of mental capacity law, namely that people have the right to make decisions that others might consider unwise, irresponsible or imprudent. The worry is that a test based on outcome-on whether what a patient decides to do is desirable or not as evaluated by a mental capacity assessor, for instancewould interfere with the right that the law is largely designed to protect.

Second, mental capacity is task specific, which means that capacity is to be assessed for each decision a patient might make. It follows that a patient might be competent regarding one kind of decision, say, a simple decision regarding treatment or a financial transaction, but incompetent regarding other kinds of decisions. On the face of it, we might consider the difficulty of decision to reflect what is at stake, the idea being that the riskier the decision, the more difficult the decision is to make. However, although a higher risk decision might be more difficult to make, it is unclear this need always be the case.

Third, note that according to mental capacity law, decisional capacity is all or nothing. A person either does or does not have capacity; there is no such thing as degrees of capacity. This is because the legal notion of capacity serves as a threshold concept that functions to distinguish between those who should retain decisional authority and those who should not (see, Buchanan and Brock 1989: 26-29).

The third point serves to remind us what is at stake when assessing whether someone has decision-making capacity, namely that of whether someone should be permitted to exert substantial autonomy over what happens to them. The point deserves emphasizing because as Paul Appelbaum puts it, 'there is no more profound infringement of the rights of citizens than the determination that they are incompetent' (Appelbaum 1998: 374). For this reason, it is critical that decisional capacity assessors are confident beyond all reasonable doubt that the person whose decisional capacity they are assessing really does lack the relevant decisional abilities before finding that person to lack capacity.

It is imperative also that lawmakers set the bar for capacity at the right level. Set the bar too high and people whose decisional capacity should not be in doubt will be at risk of having their decisional authority removed from them. Set the bar too low and people whose decisional capacity should be in doubt will be at risk of causing harm to themselves. Again, the functional test for capacity-comprising key decisional abilities-is the product of lawmakers' attempt to set the bar at the appropriate level, one that succeeds in protecting vulnerable adults from causing themselves harm, while at the same time ensuring that most people can make decisions regarding significant aspects of their lives for themselves. 


\section{Decision-Making Capacity and Personality Change Concomitant with TBI}

It has long been known that a moderate-to-severe TBI can alter someone's personality, those largely non-cognitive qualities or traits (including a person's values, emotions, preferences, and desires) that make-up a person's character or what a person is like. Probably the best-known case of personality change caused by TBI is that of Phineas Gage (1823-1860), who suffered extensive frontal lobe damage when an iron rod penetrated his skull while working on a railroad in the US during the 1840s. John Harlow, Gage's doctor at the time, describes vividly the changes that occurred to Gage's personality:

Gage was fitful, irreverent, indulging at times in the grossest profanity (which was not previously his custom), manifesting but little deference for his fellows, impatient of restraint or advice when it conflicts with his desires, at times pertinaciously obstinate, yet capricious and vacillating, devising many plans of future operations, which are no sooner arranged than they are abandoned in turn for others appearing more feasible. A child in his intellectual capacity and manifestations, he has the animal passions of a strong man. Previous to his injury, although untrained in the schools, he possessed a well-balanced mind, and was looked upon by those who knew him as a shrewd, smart businessman, very energetic and persistent in executing all his plans of operation. In this regard his mind was radically changed, so decidedly that his friends... said he was 'no longer Gage'.

\section{(Harlow 1868)}

Personality changes concomitant with a moderate-tosevere TBI need not always be as violent or damaging as those undergone by Gage. Indeed, TBI can sometimes lead to positive changes in personality (King et al. 2017). Nevertheless, a moderate-to-severe brain injury can often lead to a person acquiring negative or challenging personality traits (see, for example, Crowe 2008). For instance, people with a moderateto-severe TBI can be irritable and aggressive (Rao et al. 2009). They might also be more impulsive and less inhibited (McAllister, 2008, Rochat et al. 2013). ${ }^{3}$ As a result, such people may be more inclined to engage in behaviours that threaten

\footnotetext{
${ }_{3}^{3}$ See also the Diagnostic and Statistical Manual of Mental Disorders, $5^{\text {th }}$ edition (DSM-5) (n.d), which considers personality change (including, disinhibition, apathy, suspiciousness and aggression) as a common symptom supporting a diagnosis of major or mild neurocognitive disorder due to traumatic brain injury. See as well the International Statistical Classification of Diseases and Related Health Problems, $10^{\text {th }}$ edition (ICD-10) (n.d), which considers impulsivity and associated changes in behaviour as a common symptom of organic personality disorder and which can be caused by TBI.
}

to cause them harm, such as gambling, heavy drinking, spending money on expensive or inessential items and having sexual relations with people they do not know. And it is these potentially negative effects of personality change on peoples' decision-making that makes this group of people of particular concern to those whose role it is to assess whether capacity is present.

So, does personality change concomitant with moderateto-severe TBI deprive people of decisional capacity? The answer insofar as legal capacity is concerned depends on whether a person retains those decisional abilities constitutive of capacity. Now, there is no suggestion that a personality change need impair a person's ability to understand and retain information relevant to the decision at hand. One might support that people with personality change are unlikely to understand the social or emotional consequences of certain decisions. But putting aside the question of whether people with moderateto-severe TBI fail to have such an understanding, legal judgment in England and Wales has found against the use of a 'social-consequences' test. ${ }^{4}$

If there is a failure of capacity, then it is the ability to deliberate or use and weigh information that is likely to be relevant. Now, on the face of it, we might think that personality change concomitant with brain injury does not impair the ability in question. To be sure, a personality change might lead to a difference in how information is used or weighed. For instance, someone who is no longer averse to the risks attached to spending money on expensive goods is likely to weigh information pertaining to such risks differently than prior to undergoing a personality change. But that does not mean the person is deprived of the ability to use and weigh information relevant to the making of financial decisions.

It is curious, then, that mental capacity guidance and academic commentary suggests that personality change concomitant with a moderate-to-severe TBI can result in an impairment to the ability to reason or deliberate. In particular, impulsivity is a personality trait sometimes acquired by people with moderate-to-severe TBI that has been associated with the loss of an ability to use or weigh information relevant to the making of a decision. Thus, with regard to mental capacity guidance, subsection $\mathrm{s} 4.22$ of the MCA Code of Practice states:

\footnotetext{
${ }^{4}$ See Mr Justice Bodey's judgement in the case of A Local Authority v A [2010] when considering whether the ability to understand information relevant to making a decision should include understanding the emotional and social consequences of refusing contraception - what Bodey $\mathrm{J}$ referred to as a 'social-consequences test'. Bodey J writes at para [61]: 'I am persuaded that this wider test would create a real risk of blurring the line between capacity and best interests. If part of the test were to involve whether the woman concerned understood enough about the practical realities of parenthood, then one would inevitably be in the realms of a degree of subjectivity, into which a paternalistic approach could easily creep.'
} 
Some people who have serious brain damage might make impulsive decisions regardless of information they have been given or their understanding of it.

Unhelpfully, the MCA Code of Practice does not explain why making impulsive decisions regardless of information the person has been given or their understanding of it can indicate a failure to be able to use and weigh information. For a clearer and more comprehensive explanation of how personality change might impair capacity, we need to turn to the academic commentary.

In a number of recent works, Gareth Owen and colleagues explore what might be amiss in cases of brain-injured people who are susceptible to making impulsive decisions (Owen et al. 2015, Owen et al. 2018a). From their observations of patients with acquired brain injury, the authors identify three abilities that they take to be involved in being able to use and weigh information relevant to the decision at hand. The first is the 'ability to have 'real-time, online' awareness of deficits and impairments' (2018a:15). Owen and colleagues found that although patients may be retrospectively or concurrently aware of the existence of certain deficits, patients were often unable to use that awareness to inform their 'navigation of the decision situation'. For example, one patient expressed awareness of having difficulties in controlling their temper at the very same time they were losing their temper with another patient, thereby evidencing an inability to use their awareness to moderate their behaviour (Owen et al. 2018a:13).

The second ability is that of being able 'to detach and engage with impulses and behavioral cues afforded by the decision situation' (2018a:15). What the authors mean by this is that certain environmental cues automatically trigger certain behaviours in the person without that person first engaging in a process of deliberation or evaluation. For instance, a person might act on an impulse to spend money or drink heavily without stopping to deliberate regarding the suitability of that response.

The third ability the authors identify is the 'ability to prefigure a decision situation by being attuned to relevant normative features' (2018a:16). Drawing on the neuroscience literature (e.g. Bechara et al. 1994, Bechara et al. 1999, Damasio 1994) and their own qualitative data, the authors give reason for thinking that patients with brain injury lack certain emotions ('somatic markers') that help to guide people in their decision-making by way of serving to provide people with an awareness of relevant norms of behaviour.

We might distinguish, then, between two groups of people with moderate-to-severe TBI whose personality change influences their decision-making. On the one hand, we find that group comprising people who retain the ability to weigh or use information, albeit in a way that differs from how they would use or weigh the information were they not suffering a moderate-to-severe TBI. On the other hand, we find that group comprising people who have acquired an impulsive trait and who as a result may be unable to deliberate or use information. Acknowledge that the existence of the two groups pose decisional capacity assessors with a significant and unique challenge, insofar as assessors need to exercise care when assessing which of the two groups someone with a TBI belongs. The challenge is particularly acute, since members of both groups might engage in decision-making with similar outcomes, including outcomes that are harmful to the person in question. However, whereas the law permits the removal of decisional authority from members of the first group, the law does not permit the removal of decisional authority from members of the second group. Capacity assessors need to be diligent when assessing capacity, then, and not be led into thinking that someone whose personality has changed must be decisionally incapable solely because that person is now more inclined to make unwise or bad decisions. ${ }^{5}$

\section{Challenges to the Law}

In what follows, two challenges that cases of TBI with personality change present for the law are spelt-out. The first challenge questions whether the law provides decisional capacity assessors a principled way of distinguishing between impulsive people with moderate-to-severe TBI and impulsive people in the healthy population that would justify finding only the former as being incompetent. The second challenge questions whether by requiring people to be able to deliberate or weigh and use information, the law wrongly violates the sovereignty rights of people who are impulsive or spontaneous by nature.

\footnotetext{
${ }^{5}$ The risk of proper care or diligence not being exercised by capacity assessors is illustrated nicely by the case of $V v R$ [2011]. One of the claimant's doctors, whose testimony was used by the judge when finding the claimant to lack capacity with respect to the making of certain financial decisions, stated:

[D]uring my interview with [V] I noted that she was unable to weigh up the consequences of her actions taking into account relevant information, even though she understood the issues involved. For example, she said that she would take the offer of a sum of money won in a competition because she wanted it straight away. She would not consider whether she actually needed the money at the time or the virtue of delaying receipt in return for an extremely favourable large sum. In my opinion, this response to formal questions in a consulting room corresponds to the impulsive and irresponsible behaviour which she shows and acknowledges in the real world...

Now, there is no implication the claimant was competent with respect to the making of financial decisions. However, by describing the claimant's behaviour as 'irresponsible' the doctor was drawing on a consideration that we might think is immaterial as far as a finding of incapacity is concerned. For, again, the relevant issue insofar as the law is concerned is not that of whether a person engages in irresponsible behaviour but that of whether a person has the ability to use and weigh information relevant to the making of a decision. The latter issue is an empirical matter regarding the possession of an ability required by law for mental capacity, whereas the former issue pertains to the making of a value judgment (namely, that of whether a person has behaved responsibly or not), and is a matter that the law views as irrelevant for the purpose of assessing capacity.
} 


\section{The Overlap Challenge}

Impulsivity is a trait found in the healthy population and not only in those who have suffered a TBI. This gives rise to the worry that if impulsivity can render a person incompetent, then capacity law may entail that many people in the healthy population are incompetent. Call this the overlap challenge. The overlap challenge is a version of what Owen and colleagues call the overlap problem (Owen et al. 2018a). However, whereas Owen and colleagues construe the overlap problem as a challenge for mental capacity assessors, namely, that of how assessors are to distinguish between impulsivity in cases of TBI and impulsivity as found in the healthy population, the overlap challenge is being construed here as a challenge to the law itself.

There are two ways we might try to answer the overlap challenge, both of which seek to show that the law does not entail that impulsive people in the healthy population are incompetent. Neither way is without its difficulties. First, we could argue that only in the TBI case do we find a loss or impairment of ability to deliberate or use and weigh information. Here, the basic idea is that impulsive people within the healthy population could act less impulsively should they decide, whereas those with a moderate-to-severe TBI lack the ability to behave in a way that would qualify as using and weighing information relevant to the decision at hand. Owen and colleagues appear to advance such an idea when they write:

The crucial point is that, for some patients, that impulsive behavior is born of underlying inabilities that themselves render decision making impossible, at least for certain classes of decision. Impulsivity of this sort differs... in kind from the impulsivity of an individual who has the relevant abilities but in particular instances chooses not to exercise them.

\section{Owen et al. (2018a:17)}

But do impulsive people within the healthy population possess abilities involved in the making of more measured decisions? To be sure, there are likely to be some people who act impulsively on occasion and who might have behaved in more measured ways if they chose. However, on the face of it, many impulsive people have little ability to deliberate regarding the decisions they make, at least at the time of making those decisions. Impulsive buyers, for instance, very often seem to be people who are carried away with desires or impulses to spend money on certain goods, and who at the time of making those decisions have little ability to step back and deliberate on the wisdom of what they are about to do. This is why we tend to think of impulsiveness as a personality trait that shapes or defines a person and by so doing sets parameters to the decisions a person is able to make. At the very least, the claim that many impulsive people within the healthy population have decisional abilities that those with moderate-to-severe TBI lack would need to be empirically shown and not just assumed to be true.

The second way we might try to distinguish between people whose impulsivity is caused by TBI and people whose impulsivity is not caused by TBI draws on the fact that the impairment of the ability to deliberate is likely only to be a necessary condition for a finding of incapacity. It is unlikely to be sufficient because in addition the loss of the ability to deliberate is likely to need to result from some psychological or neurological impairment or disturbance. Indeed, the MCA two-stage functional test of capacity outlines such a requirement. According to that test, a person lacks mental capacity only if (1) that person suffers from an impairment or disturbance in the functioning of the mind or brain and (2) the impairment or disturbance in the mind or brain is such that the person is incapable of making a decision. The idea might then be that even if impulsive people within the healthy population lack the ability to deliberate or use and weigh information, they do not lack decisional capacity, because their lack of ability is not due to an impairment in the functioning of the mind or brain.

The idea is an attractive one. It is tempting to think impulsive people with moderate-to-severe TBI might lack capacity because their inability to deliberate is due to some psychological or neurological impairment. However, the idea is not without its difficulties. To begin with, notice the justification for distinguishing between the TBI case and the non-TBI case requires us to be able to draw a clear distinction between the inability to deliberate and the impairment or disturbance in the mind or brain that is supposed to be the cause of the inability. Only then do we have a way of distinguishing between impulsive people with brain injury and impulsive people without brain injury. But it is unclear as to whether the inability and the mental or neurological impairment that is supposed to be the cause of the inability can be clearly distinguished, since it might be reasonably supported that the impairment in mind or brain from which a person is suffering just consists in the person's inability to deliberate.

Moreover, even supposing we can draw such a distinction, we will need to be able to show that only in the TBI case is the inability to deliberate due to an impairment in the mind or brain. However, we need to take seriously the possibility that impulsive people with brain injury and impulsive people without brain injury have very similar psychological and neurological mechanisms underlying their inability to deliberate. And if that turns out to be the case, then, again, we appear to lack a principled way of distinguishing between impulsive people with TBI and impulsive people within the healthy population. 
Neither way of seeking to draw a distinction between TBI impulsivity and impulsivity within the healthy population is without its problems. The first way dubiously assigns certain decisional abilities to impulsive people within the healthy population. Even if some people within the healthy population who behave impulsively on occasion have such abilities, it is doubtful if this is true of many impulsive people within the healthy population. The second way of drawing a distinction arguably fails to show that impulsive people in the healthy population have capacity, since it remains unclear as to how to justify attributing an impairment in the mind or brain to impulsive people with TBI but not to those without.

To conclude, it is worth spelling out a couple of reasons why the overlap challenge is a significant problem for the law. First, putting aside the question of whether in practice most capacity assessors are likely to interpret the law in a way that would lead them to find incompetent many impulsive people within the healthy population, the idea the law might imply that such people are incompetent is a very worrisome one. Good law needs to protect people from potential misuses of power. This requires the law to be clear and precise regarding the circumstances in which capacity assessors can find a person decisionally incompetent and potentially remove decisional authority from them. ${ }^{6}$

Second, note the overlap challenge also throws into question the legitimacy of a law that permits removal of decisional authority from impulsive people with moderate-to-severe TBI. This is because if we lack a principled way of distinguishing between impulsive people with moderate-tosevere TBI and impulsive people in the healthy population that justifies finding only the former as being incompetent, and we are of the view that the law should consider impulsive people in the healthy population to have capacity, then we will be very hard-pressed to explain what could justify the law removing decisional authority from people with moderateto-severe TBI. In other words, if the law should consider impulsive people in the healthy population to have capacity (as the law surely should), then the law risks being arbitrary and discriminatory if it does not say or imply the same in relation to people with moderate-to-severe TBI.

\footnotetext{
$\overline{6}$ That capacity assessors normally consider such things as normative data and analysis of significant change when assessing capacity might be taken to support the idea that there is near-negligible risk of impulsive people within the healthy population being found incompetent. However, even if the risk of such people being found incompetent is small, we should have real concerns regarding a law that implies that such people are without capacity. Again, the law exists to protect people from unwarranted intrusion into their lives, including by those whose role it is to assess capacity. Claiming it does not matter much whether the law entails that people within the healthy population are incompetent because we can rely on the good judgement of mental capacity assessors, is a little like saying we do not need child-safeguarding laws because we can rely on those whose role it is to protect children to behave always in their best interests.
}

\section{The Valuing Spontaneity Challenge}

The overlap challenge calls on the law to explain why it does not entail that impulsive people in the healthy population are incompetent. If successful, the overlap challenge should give us serious pause for reflection. The valuing spontaneity challenge builds on the overlap challenge by way of giving positive reasons for thinking that impulsivity is not the kind of thing that should disqualify someone from being allowed to make decisions regarding significant aspects of their lives for themselves.

Recall that the law has been anxious to avoid an outcome test for capacity, opting instead for a process test. Recall also that a primary justification for this is to allow people to be able to make decisions in a way that accords with their own values and preferences. To the extent that people are able to deliberate regarding what to do or decide, the outcome of that process of deliberation should be respected regardless of whether the outcome is a good one or not. But why should the requirement to respect a person's decision-making apply only to the outcome of the decisional process and not the decisional process itself? What if someone does not care about deliberating or using and weighing information, for instance? Indeed, this seems to describe people who are impulsive, people who value or care about making decisions instinctively or spontaneously without thinking through the consequences of those decisions.

The valuing spontaneity challenge, then, challenges the law to give an account of why it assigns to reasoning or deliberation such a lofty status. Without giving such an account, it is difficult to avoid the worry that the legal notion of capacity unjustifiably displays a strong 'rationalist' bias, one that favours a personality type associated with those who live their lives in ways that are careful, considerate and reflective, but not those who live their lives in ways that are carefree and spontaneous.

Now, one way of responding to the valuing spontaneity challenge is to point out that the law does allow people to be impulsive if they have the ability to deliberate or use and weigh information. But as we saw when discussing the overlap challenge, it is not clear whether impulsive people at large do have the abilities in question. Moreover, even supposing that impulsive people do possess the abilities on occasion, it is unclear whether this response answers the valuing spontaneity challenge. For that challenge is about respecting people's right to behave in a spontaneous or impulsive way, and that challenge seems to hold regardless of whether a person is able to act in ways that are not impulsive. Imagine two people who are impulsive in equal measure. Suppose that one person has the ability to behave in a more measured way, whereas the other person does not. It is difficult to see why this difference between the two is relevant to whether one or both should retain decisional authority. We are supposing that both people 
are engaging in identical behaviours and are engaging in those behaviours for the same reasons, namely reasons that relate to their impulsivity. Insofar as decisional outcome and decisional process are concerned, there is no difference between the two cases. So, what could justify insisting that one of these people should be allowed to retain decisional authority but not the other?

Another response to the valuing spontaneity challenge might be to question whether impulsive people do value behaving impulsively. Owen and colleagues observe that some of the people with acquired brain injury they interviewed appeared to express regret for the decisions they made (2018b: 31). We might take such findings to support the idea that these people's impulsive decision-making did not truly reflect their values. But the issue of what a person really or truly values or wants is a vexed one. Should we take a person's professed values (either at the time of behaving a certain way or later) to be an accurate indication of what that person's really values? Or is a person's actual behaviour a better indication of what the person truly values? In this regard, note how we would likely doubt someone who claims not to value acting impulsively but who all the same persistently behaves in an impulsive way.

\section{Conclusion: Does the Law Need to Change?}

The case of TBI with personality change raises a number of challenges to mental capacity law, and especially the law's insistence that decisional capacity requires the ability to deliberate or use and weigh information. The first challenge asks why the law does not imply that impulsive people within the healthy population lack capacity, since arguably, many of these people lack the ability to deliberate. The second challenge asks whether by requiring people to be able to deliberate or weigh and use information the law wrongly violates the sovereignty rights of people who are impulsive or spontaneous by nature.

Is a change in law needed? We have here a number of considerations that speak in favour of a change in the law. However, any change in the law would need to satisfy a number of requirements (Whiting, 2015; see also Appelbaum 1998, Berg et al. 1996, Coggon and Miola 2011). ${ }^{7}$ These include requirements of proportionality (the change needs to bring about more benefit than harm), effectiveness (the change needs to lead to a desired outcome), necessity (there should be no better alternative ways of achieving the outcome), equity (the change should not lead to some people being more

\footnotetext{
${ }^{7}$ The requirements listed are familiar from other contexts (for instance, Childress et al. 2002 outline several such requirements with respect to the evaluation of public health interventions; see also Brown and Whiting 2014, who draw on such requirements for the purpose of evaluating distressing health promotion advertising).
}

favourably treated than others) and minimal infringement (the change must interfere minimally with people's liberties).

Now, one might support that a law that no longer demands people to have the ability to deliberate would threaten a proportionality requirement. For instance, people with moderateto-severe TBI make up a vulnerable group, and for that reason, we might feel they need protecting from their decision-making, even if this means they would be prevented from behaving in ways they value or desire. We might also point out that even if people with moderate-to-severe TBI lack capacity according to existing law, decisions will still need to be made in their best interests. This may often require surrogate decisionmakers to make decisions that respect what a person lacking capacity desires, since people's desires and preferences are relevant to an assessment of people's best interests. We might, then, take the view that the risks attached to the legal status quo are perhaps not all that great, at least when compared with the risks that are attached to a change in the law.

Yet against the above reasons for retaining the legal status quo, we might take the view instead that the harm the law causes by removing decisional authority from those who are impulsive is no lesser a harm than the harm the law would cause were it to remove decisional authority from those who are more rational or reflective by nature. We might also retain significant worries regarding the inequity of a law that allows impulsive people within the healthy population to have decisional authority but not those with moderate-to-severe TBI. And we might consider as well whether there are other ways of supporting impulsive people with and without TBI that does not require stripping them of their decisional authority.

The paper began by claiming that we should remain open to the possibility that despite lawmakers' best efforts, the law has it wrong. Again, it is unclear as to whether reflection on cases of personality change concomitant with TBI gives us sufficient reason for thinking the law needs changing, but it encourages us to take seriously the question of whether the bar for capacity has been set at an appropriate level.

Thoughts and practice recommendations for mental capacity assessors:

- This paper is a critique of English and Welsh law. If the critique is successful, then that constitutes a strong case for thinking that lawmakers might need to review and revise mental capacity law.

- The paper does not seek to recommend changes in how capacity assessors assess capacity, however. Mental capacity assessors need to work within the law, regardless of whether a change in the law (for instance, a change to the legal criteria for capacity) is warranted or not.

- Nevertheless, the views of capacity assessors (along with other stakeholders) are important to the discussion of whether the law should change. Again, this paper 
advances reasons for thinking that impulsivity (or a corresponding lack of ability to deliberate or use and weigh information) should not constitute grounds for finding someone incompetent. Assessors might reflect on whether they agree.

- With regard to personality change concomitant with TBI, a distinction is drawn between cases where capacity is retained under existing law and cases where capacity is lost under existing law. Mental capacity assessors need to ensure they are able to distinguish between such cases and do not automatically assume that someone who has undergone a personality change due to a moderate-to-severe TBI lacks capacity solely because they might be more susceptible to making unwise decisions.

Acknowledgments The author would like to thank two anonymous reviewers for their helpful comments.

Open Access This article is distributed under the terms of the Creative Commons Attribution 4.0 International License (http:// creativecommons.org/licenses/by/4.0/), which permits unrestricted use, distribution, and reproduction in any medium, provided you give appropriate credit to the original author(s) and the source, provide a link to the Creative Commons license, and indicate if changes were made.

\section{References}

A Local Authority v A [2010] EWHC 1549 (Fam).

Appelbaum, P. (1998). Ought we to require emotional capacity as part of decisional competence? Kennedy Institute of Ethics Journal, 8, 377387.

Bechara, A., Damasio, A., Damasio, H., \& Anderson, S. (1994). Insensitivity to future consequences following damage to human prefrontal cortex. Cognition., 50, 7-15.

Bechara, A., Damasio, A., Damasio, \& Lee, G. (1999). Different contributions of the human amygdala and ventromedial prefrontal cortex to decision-making. The Journal of Neuroscience, 19, 5473-5481.

Berg, J., Appelbaum, P., \& Grisso, T. (1996). Constructing competence: formulating standards of legal competence to make medical decisions. Rutgers Law Review, 48, 345-396.

Brown, S., \& Whiting, D. (2014). The ethics of distress. Toward a framework for determining the ethical acceptability of distressing health promotion advertising. International Journal of Psychology, 49, 8997.

Buchanan, A. (2004). Mental capacity, legal competence, and consent to treatment. Journal of the Royal Society of Medicine, 97, 415-420.

Buchanan, A., \& Brock, D. (1989). Deciding for others: The ethics of surrogate decision making. Cambridge: Cambridge University Press.

Childress, J., Faden, R., Gaare, R., Gostlin, L., Kahn, J., \& Bonnie, R. (2002). Public health ethics: Mapping the terrain. The Journal of Law, Medicine, and Ethics, 30, 169-177.
Coggon, J., \& Miola, J. (2011). Autonomy, liberty, and medical decisionmaking. Cambridge Law Journal., 70, 523-547.

Crowe, S. (2008). The behavioural and emotional complications of traumatic brain injury. New York: Taylor and Francis.

Culver, C., \& Gert, B. (1990). The inadequacy of competence. Milbank Quarterly, 68, 619-643.

Culver, C., \& Gert, B. (2004). Competence. In J. Radden (Ed.), The philosophy of psychiatry: A companion (pp. 258-270). Oxford: Oxford University Press.

Damasio, A. (1994). Descartes' error: Emotion, reason, and the human brain. In New York: Putnam Publishing.

Diagnostic and statistical manual of mental disorders, 5th edition: DSM5. Washington: American Psychiatric Publishing.

Grisso, T., \& Appelbaum, P. (1998). Assessing competence to consent to treatment: A guide for physicians and other health professionals. Oxford: Oxford University Press.

Harlow, J. (1868). Recovery from the passage of an iron bar through the head. Publications of the Massachusetts Medical Society, 2, 327347.

International Statistical Classification of Diseases and Related Health Problems, $10^{\text {th }}$ edition: $I C D-10$ (n.d). World Health Organisation.

King, M., Manzel, K., Bruss, J., \& Tranel, D. (2017). Neural correlates of improvements in personality and behavior following a neurological event. Neuropsychologia. https://doi.org/10.1016/j. neuropsychologia.2017.11.023.

McAllister, T. (2008). Neurobehavioral sequelae of traumatic brain injury: Evaluation and management. World Psychiatry, 7, 3-10.

Mental Capacity Act 2005. Available at: http://www.legislation.gov.uk/ ukpga/2005/9/contents Accessed on 26 Nov 2019.

Mental Capacity Act Code of Practice. London: The Stationery Office Available at: https://www.gov.uk/government/publications/mentalcapacity-act-code-of-practice.

Owen, G., Freyenhagen, F., Martin, W., \& David, A. (2015). Clinical assessment of decision-making capacity in acquired brain injury with personality change. Neuropsychological Rehabilitation.

Owen, G., Freyenhagen, F., \& Martin, W. (2018a). Assessing decisionmaking capacity after brain injury: A phenomenological approach. Philosophy, Psychiatry, and Psychology, 25, 1-19.

— (2018b). Authenticity, insight, and impaired decision-making capacity in acquired brain injury. Philosophy, Psychiatry, and Psychology, $25,29-32$.

Rao, V., Rosenberg, P., Bertrand, M., Salehinia, S., Spiro, J., Vaishnavi, S., Rastogi, P., Noll, K., Schretlen, D. J., Brandt, J., Cornwell, E., Makley, M., \& Miles, Q. S. (2009). Aggression after traumatic brain injury: prevalence and correlates. The Journal of Neuropsychiatry and Clinical Neurosciences, 21, 420-429.

Rochat, L., Beni, C., Annoni, J. M., Vuadens, P., \& Van der Linden, M. (2013). How inhibition relates to impulsivity after moderate to severe traumatic brain injury. Journal of the International Neuropsychological Society, 19, 1-9.

V v R [2011] EWCH 822 (QB).

Whiting, D. (2015). Evaluating medico-legal decisional competency criteria. Health Care Analysis, 23, 181-196.

Publisher's Note Springer Nature remains neutral with regard to jurisdictional claims in published maps and institutional affiliations. 